\title{
Brazil Nut (Bertholletia excelsa, Lecythidaceae) Regeneration in Logging Gaps in the Peruvian Amazon
}

\author{
Julian Moll-Rocek, ${ }^{1}$ Matthew E. Gilbert, ${ }^{2,3}$ and Eben N. Broadbent ${ }^{1,3}$ \\ ${ }^{1}$ Department of Organismic and Evolutionary Biology, Harvard University, 16 Divinity Avenue, Cambridge, MA 02138, USA \\ ${ }^{2}$ Department of Plant Sciences, 1210 PES, Mail Stop 1, University of California at Davis, CA 95616, USA \\ ${ }^{3}$ Sustainability Science Program, Kennedy School of Government, Harvard University, 79 JFK Street, Cambridge, MA 02138, USA
}

Correspondence should be addressed to Julian Moll-Rocek; jmollrocek@post.harvard.edu

Received 17 November 2013; Accepted 16 February 2014; Published 25 March 2014

Academic Editor: Piermaria Corona

Copyright (C) 2014 Julian Moll-Rocek et al. This is an open access article distributed under the Creative Commons Attribution License, which permits unrestricted use, distribution, and reproduction in any medium, provided the original work is properly cited.

\begin{abstract}
Brazil nut (Bertholletia excelsa Bonpl.) extraction serves as an important economic resource in the Madre de Dios region of Peru simultaneously promoting forest conservation, yet, under current management, it cannot compete with other land uses. This study investigated the effects of logging gaps on Brazil nut natural regeneration. A total of 48 paired logging gap-understory sites were visited in Brazil nut concessions in the Tambopata province of Madre de Dios, Peru. At each site, the number of Brazil nut recruits was counted and canopy openness and gap area were measured. Significantly higher levels of recruit density were found in logging gaps than in understory sites. Additionally, recruit density was positively correlated with canopy openness. Further, in experimental plantings in paired gap and understory sites, canopy openness, height, total leaf area, and number were recorded from August 2011 to February 2012. Height, total leaf area, and leaf number were significantly higher for tree-fall gap grown seedlings, lending further evidence to improved recruitment success of Brazil nuts in forest gaps. These results suggest that multiple-use forest management could be considered as an alternative for the sustainable extraction of Brazil nuts but also highlight that further studies are required.
\end{abstract}

\section{Introduction}

Brazil nut (Bertholletia excelsa, Bonpl) is a gap-dependent canopy emergent tree requiring high light levels to reach maturity $[1,2]$ and that relies on scatter-hoarding agoutis (Dasyprocta sp.) to release seeds from the woody pericarp fruit [3]. The long-term demographic viability of Brazil nut populations currently relies on purely natural regeneration. The existing density of mature B. excelsa trees, largely responsible for determining natural regeneration rates, is lower in Madre de Dios, Peru (0.5-1.5 individuals $\mathrm{ha}^{-1}$ ) [4] than in neighboring Acre, Brazil (1.5-2.5 ind. ha ${ }^{-1}$ ) [5] and Pando, Bolivia (2.5-3.0 individuals ha ${ }^{-1}$ ) [1].

Commercially, the seeds of B. excelsa (commonly referred to as Brazil nuts) are an economically important nontimber forest product (NTFP) contributing an estimated $\$ 8$ million USD to Peru's GDP annually [6], \$73 million in Bolivia [7], and $\$ 30$ million in Brazil [8]. Within Madre de Dios, as much as $22 \%$ of the local residents rely directly or indirectly on Brazil nut harvest for their economic livelihoods [9]. The ecological sustainability of Brazil nut extraction is disputed with some researchers alluding to an imminent demographic collapse [10], while others suggest stable populations with current extraction rates [11-13].

Brazil nut has been celebrated as having the potential to reconcile forest conservation and development objectives [14]. Yet, doubts have been raised surrounding the success of Brazil nut harvesting as a means to reduce forest degradation [9], as it is not economically competitive with other land uses $[12,15]$. Selective logging has the potential to allow both commercial timber extraction simultaneous to extraction of nontimber forest products [16]. Since 2004, selective logging has been permitted within Brazil nut concessions in Madre de Dios as a complementary income source. However, the potential effects of selective logging on natural regeneration have been poorly studied so far. Soriano et al. [17] found 
that in Pando, Bolivia, levels of Brazil nut regeneration in selectively logged forests suggested compatibility with timber harvesting.

To our knowledge, the current study is the first to investigate the effect of logging gaps on $B$. excelsa natural regeneration in the Peruvian Amazon. Specifically, we studied Brazil nut recruit density (seedlings, saplings, and juveniles) in logging gaps paired with understory plots in active Brazil nut concessions in Madre de Dios, Peru. We investigated the importance of (a) logging gaps or understory sites; (b) canopy openness; and (c) distance to the nearest reproductively mature tree, on recruitment. Our hypothesis was that higher light availability would favor $B$. excelsa regeneration in logging gaps. These data were complimented by a comparative seedling growth experiment investigating the importance of canopy openness on height, total leaf area, and leaf number in tree-fall gaps and understory environment, with the aim to provide further understanding of Brazil nut recruitment success.

\section{Materials and Methods}

2.1. Study Site. We selected 16 active Brazil nut concessions as study sites in Tambopata Province, Department of Madre de Dios, Peru $\left(12^{\circ} 04^{\prime} 19^{\prime \prime}-12^{\circ} 17^{\prime} 52^{\prime \prime} \mathrm{S}\right.$ and $69^{\circ} 00^{\prime} 52^{\prime \prime}-$ $69^{\circ} 16^{\prime} 41^{\prime \prime} \mathrm{W}$, approximate elevation 190 masl). Fieldwork was conducted during the 2011 dry season (June-August, 2011). The area receives $2500-3500 \mathrm{~mm}$ of rain per year and has stable average temperatures around $24^{\circ} \mathrm{C}$ [18]. The Brazil nut concession system was established in the year 2000 by the Peruvian government, which granted 40-year leases exclusively for Brazil nut extraction in Madre de Dios. Since 2004, mechanized timber extraction in Brazil nut concessions has been allowed on a selective basis. Currently, Brazil nut concessions in Madre de Dios cover an area of 1 million ha [19].

Brazil nut concessionaires were previously interviewed to understand Brazil nut management within these units. These 16 concessions (ranging in area from 125 to 1000 ha; Table 2) were selected based on concessionaires knowledge of the locations of 1-5-year-old logging gaps arising from selective logging of timber species other than Brazil nut. In each concession, three logging gaps, each paired with an area of understory forest located at least $50 \mathrm{~m}$ away in a random direction, were sampled for a total of 48 paired plots. Individual logging gaps were identified either with the assistance of concession owners or by following skid trails based on their instructions. Gap sizes ranged from 120 to $290 \mathrm{~m}^{2}$ with a mean \pm std. deviation of $218 \pm 34 \mathrm{~m}^{2}$.

2.2. Measurement of Recruit Density. Plot length was measured from the center of the stump to the first bifurcation at the base of the crown of the felled tree (Supplementary materials A in Supplementary Material available online at http://dx.doi.org/10.1155/2014/420764), with a width of $10 \mathrm{~m}$ (roughly the width cleared during postlogging timber processing) $(12-29 \mathrm{~m}$, mean $=21.8 \mathrm{~m})$. The corresponding paired understory plot was established with the same length and width. The length measurement often excluded a large portion of the logging gap where the canopy lay. Whereas the measured area was cleared for sawing planks, the excluded canopy areas were characterized by large amounts of branches and debris. In each plot, all size classes of B. excelsa were sampled and had their height recorded. Size classes were seedlings $(<1.3 \mathrm{~m})$, saplings $(1.3 \mathrm{~m} \geq 10 \mathrm{~cm} \mathrm{dbh})$, and juveniles $(>10 \mathrm{~cm} \mathrm{dbh})$. Four canopy openness measurements were taken using a convex canopy densiometer [20, 21] held at $1.5 \mathrm{~m}$ height at each of the three points within the gap: the stump, center of the gap, and base of the crown. These were averaged together for a single canopy openness estimate for each plot. Canopy openness was measured at corresponding points in the paired understory plot. To assess whether distance to the closest reproductively mature tree affected regeneration density, the nearest mature Brazil nut tree (minimum $40 \mathrm{~cm}$ diameter at breast height (dbh); Zuidema and Boot [11] reported that $98 \%$ of trees were reproductive when $\geq 40 \mathrm{~cm} \mathrm{dbh}$ ) was identified by an experienced field assistant and its distance from the center of the gap was measured up to $100 \mathrm{~m}$ (modified from Kainer et al. [22]).

As the distribution of $B$. excelsa recruits deviated from a normal distribution, a nonparametric Wilcoxon sign-rank test was used to compare $B$. excelsa recruitment between gap and understory (defined as the aggregate density of seedlings $\leq 1.3 \mathrm{~m}$ tall, saplings between $1.3 \mathrm{~m}$ tall and $10 \mathrm{~cm} \mathrm{dbh}$, and juveniles $>10 \mathrm{~cm} \mathrm{dbh}$ ) in stems $\mathrm{ha}^{-1}$. Further, Poisson distribution generalized linear models of recruit density by canopy openness and recruit density by distance to the nearest mature tree were used to investigate the effects of these two variables in more detail, with the Poisson parameter estimated using maximum likelihood. Using the observed recruit density and canopy openness in each study plot in our sample, we derived a maximum likelihood estimate for the changing probability of encountering a recruit. The same was repeated for recruit density and distance to the nearest mature tree. All statistical analyses were conducted in JMP Software (JMP 9.0.1, SAS), or in R v.2.9.2 (R Development Core Team, 2009).

\subsection{Comparative Seedling Growth Experiment. In August} 2011, 64 Brazil nut seedlings were planted in 5 paired natural tree-fall gaps and understory sites in the experimental forest plot of the Universidad Nacional Amazónica de Madre de Dios (UNAMAD, $12.4702^{\circ} \mathrm{S}, 69.1426^{\circ} \mathrm{W}$ ), with 32 seedlings in each growth environment. The forest plot is characterized by terra firme forest, which is representative for the area, with approximately 68 woody species ha ${ }^{-1}$ (see Table 1 ).

Brazil nutseedlings were 9 months of age, ranged from 8 to $20 \mathrm{~cm}$ in height, and had between 3 and 17 leaves at planting. All had been grown under homogenous conditions of partial shade netting at the UNAMAD nursery located at the same site as the experimental forest plot. Seedlings were chosen randomly for planting across growth environments to avoid bias in their initial distribution. The following measurements were taken on a monthly basis between August 2011 and February 2012 for each seedling: height above the ground $(\mathrm{cm})$, length and width of each leaf, leaf number, and 
TABLE 1: The common name, scientific name, and family for the ten most frequent woody species in the UNAMAD experimental forest and Brazil nut (M. Usca, personal communication), ranked by Importance Value index (IVi) and calculated as the sum of relative density, relative frequency, and basal area. This data was collected in five $20 \times 100 \mathrm{~m}$ transects, equaling 1 ha.

\begin{tabular}{|c|c|c|c|c|}
\hline Common name & Scientific name & Family & IVi & Count \\
\hline Tamamuri & Brosimum lactescens & Moraceae & 49 & 21 \\
\hline Chimicua & Pseudolmedia laevis & Moraceae & 37 & 33 \\
\hline Cumala & Virola sp. & Myristicaceae & 35 & 17 \\
\hline Almendrillo & Laetia procera & Flacuortiaceae & 33 & 13 \\
\hline Meliosma & Meliosma sp. & Sabiaceae & 33 & 16 \\
\hline Huasai & Euterpe precatoria & Arecaceae & 27 & 31 \\
\hline Copal & Protium amazonicum & Burseraceae & 25 & 28 \\
\hline Cumala colorada & Iryanthera juruensis & Myristicaceae & 23 & 25 \\
\hline Shimbillo & Inga sp. & Fabaceae & 20 & 17 \\
\hline Moena & Ocotea sp. & Lauraceae & 18 & 15 \\
\hline Castaña & Bertholletia excelsa & Lecythidaceae & 1 & 1 \\
\hline
\end{tabular}

canopy openness directly above the seedling using a canopy densiometer. The equation for total leaf area is as follows:

$$
\mathrm{LA}_{T}=0.622(L * W)+2.36
$$

where $\mathrm{LA}_{T}=$ total leaf area $\left(\mathrm{cm}^{2}\right), L=$ leaf length $(\mathrm{cm})$, and $W=$ leaf width $(\mathrm{cm})$, which was calibrated by regressing $\mathrm{LA}_{T}$ for ten different sized leaves (measured using ImageJ64) against their $L * W\left(P<0.0001\right.$; Adj- $R^{2}>0.99 ; n=$ 10). For each monthly measurement, mean height, $\mathrm{LA}_{T}$, leaf number, and canopy openness were compared between seedlings grown in tree-fall gaps and understory sites using Bonferroni corrected $t$-tests, and linear regressions were then run between openness and height, total leaf area, and leaf number separately for felling gap and understory habitats.

\section{Results}

3.1. Recruit Density. Brazil nut concessions ranged from 125 to 1083 ha with a mean \pm SD of $569 \pm 338$ ha (Table 2). Sampled paired gap-understory sites ranged from 120 to $290 \mathrm{~m}^{2}$ with a mean \pm SD of $216 \pm 34 \mathrm{~m}^{2}$. Mean canopy openness in gap sites was $19.7 \pm 6.4 \%$, and it was $7.6 \pm 1.3 \%$ in understory sites (Table 3). A total of 16 recruits, including seedlings, saplings, and juveniles, were found in the 48 paired sites, with 12 occurring in logging gaps and 4 in understory sites (Figure 1). As gaps ages ranged from 1 to 5 years, only seedlings could have been established postlogging. To meet statistical assumptions, one outlier was omitted from all analyses where nine seedlings were germinating from a single fruit found in a logging gap; thus, the statistics were conservative as inclusion of the outlier would have enhanced the observed higher recruit density in gaps. While these results included many plots without any recruits, these data were still valuable in establishing a relation between growth environment and presence of recruits. In addition, logging gaps contained an array of early pioneer species, which are generally taller than any Brazil nut recruits present, whereas understory sites were characterized by much lower stem counts and more shade tolerant species (J. Moll-Rocek, personal observation).

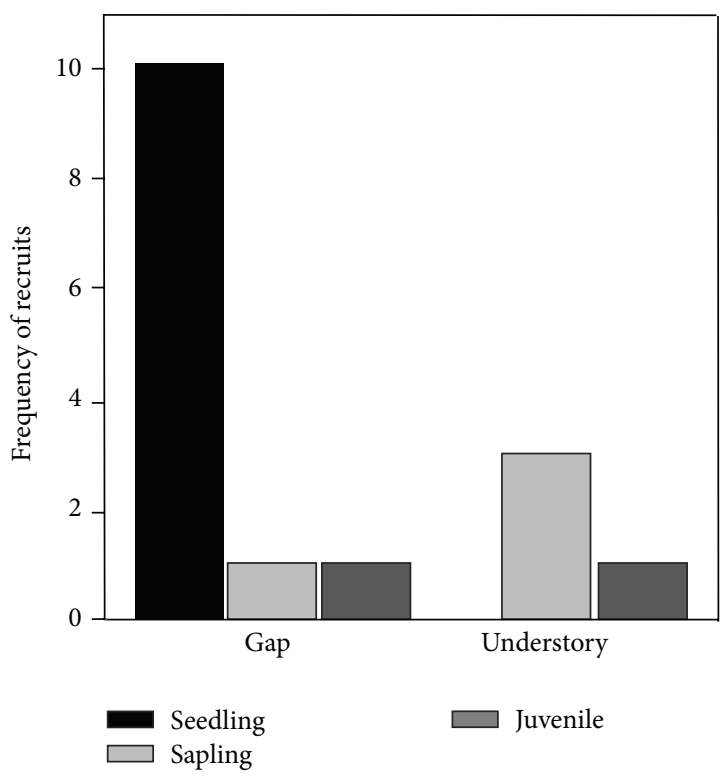

FIGURE 1: Histogram of recruit frequency by height and diameter at breast height (dbh) in gap and understory Sites. Size classes were seedlings $(<1.3 \mathrm{~m})$, saplings $(1.3 \mathrm{~m} \geq 10 \mathrm{~cm} \mathrm{dbh})$, and juveniles $(>10 \mathrm{~cm} \mathrm{dbh})$. A total of four recruits were found in understory sites and 12 recruits in logging gaps sites (Wilcoxon sign-rank, $P=0.02$, $n=47)$.

We found a significantly higher recruit density in logging gaps (11.5 ind. ha ${ }^{-1}$ ) than in understory sites ( 3.8 ind. ha $\left.{ }^{-1}\right)$, using a Wilcoxon sign-rank test $(P=0.02, n=47$, excludes outlier). Further, the Poisson distribution model yielded an increasing probability of encountering a recruit as canopy openness increased $(P=0.001, n=97)$ supporting the idea that recruit success is related to high light environments. Recruit density showed no significant relationship to distance of nearest mature tree $(P=0.4, n=97)$.

3.2. Seedling Growth. All measures of growth, including height, $\mathrm{LA}_{T}$, and leaf number were found to be significantly 


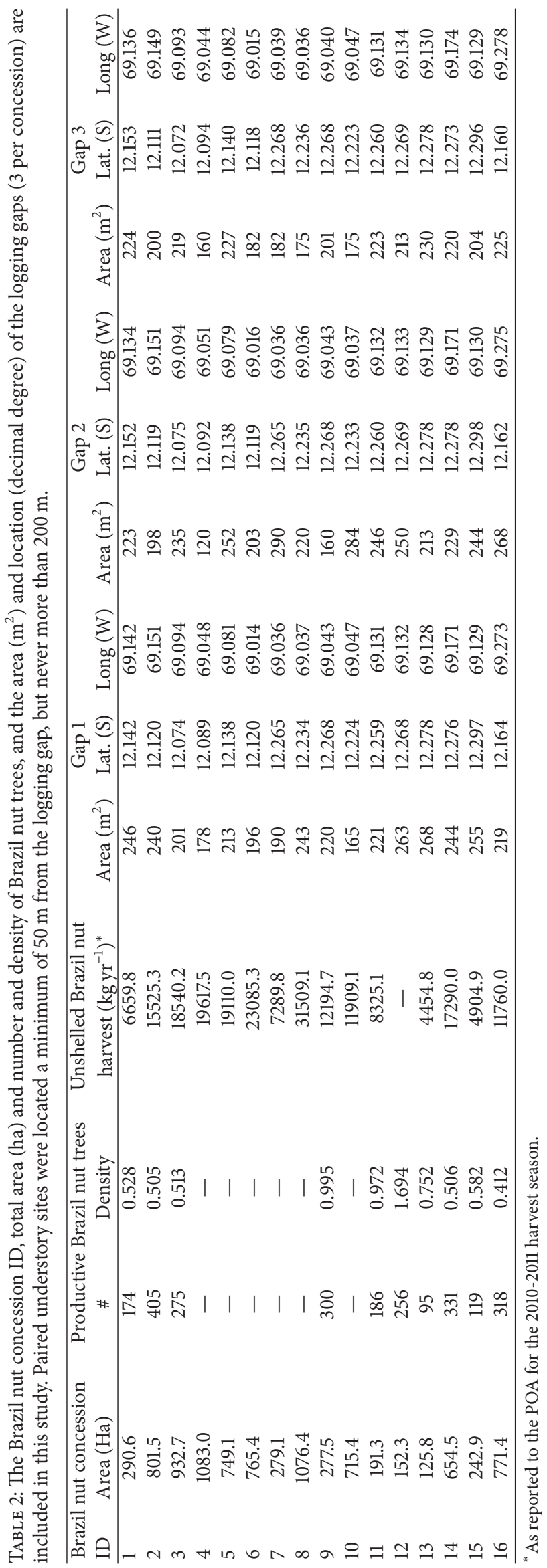


TABLE 3: Mean area, canopy openness, and recruit density compared between logging gap and understory environments. Additionally, Soriano et al's results [17] on recruit density are included. Soriano et al. [17] collected logging gap data for both informal and formal logging types, while all logging gaps in our study were due to informal logging.

\begin{tabular}{lcccc}
\hline & Mean area \pm SD $\left(\mathrm{m}^{2}\right)$ & Canopy openness \pm SD (\%) & Recruit density (ind $\cdot$ ha $\left.^{-1}\right)$ & $\begin{array}{c}\text { Soriano et al. 2012 [17] } \\
\text { Recruit density (ind } \cdot \text { ha }\end{array}$ \\
\hline Logging gap & $216.6 \pm 34$ & $19.7 \pm 6.4$ & 11.5 & ${\text { Informal: } 7.6^{*}}^{\text {Formal: }^{-1} .8^{*}}$ \\
Understory & $216.6 \pm 34$ & $7.6 \pm 1.3$ & 3.8 & $3.9^{*}$ \\
\hline
\end{tabular}

higher in tree-fall gaps than in understory sites from the fourth month onward (Figure 2). The average height in treefall gap seedlings increased by $18.4 \mathrm{~cm}$ over the course of the six months compared to an increase of $1.5 \mathrm{~cm}$ for understory seedlings. Average $\mathrm{LA}_{T}$ in tree-fall gap seedlings increased by $344.5 \mathrm{~cm}^{2}$ but decreased by $24.3 \mathrm{~cm}^{2}$ in understory seedlings over the course of the six months. As expected, canopy openness was significantly higher in tree-fall gaps throughout all 6 months of measurement. Within understory sites, openness was significantly correlated with total leaf area $(P<$ $\left.0.0001 ; \operatorname{Adj}-R^{2}=0.09 ; n=180\right)$ and leaf number $(P=$ 0.0026 ; Adj- $R^{2}=0.044 ; n=180$ ). Seedling height was not significantly correlated with openness in either understory or gap sites $(P>0.05, n=180)$.

\section{Discussion}

An improved understanding of the impacts of selective logging on Brazil nut recruitment is crucial to the long-term sustainability of Brazil nut extraction in multiple use forests. Higher recruit density in logging gaps, a positive correlation between recruit density and canopy openness, and increased growth rates in tree-fall gaps support the earlier classification of $B$. excelsa as a gap-dependent species $[1,2,5]$. Further, higher seedling growth rates in logging gaps and fallows [5, 23], which lead to improved recruitment success, were positively correlated with higher light environments. Together, these results and the literature suggest the possibility that selective logging could foster natural B. excelsa regeneration, both through enhanced establishment and growth rates, but further studies more explicitly comparing regeneration in natural forest gaps and unlogged forest understory environments are needed.

In a study of selective logging effects on natural regeneration of B. excelsa in Bolivia, Soriano et al. [17] found no significant difference in recruitment between logged and understory sites (Table 3 ). The difference between these findings and those in our study may be due to how Soriano et al. [17] defined logged sites, which included skid trails, access roads, and log landings in addition to logging gaps. Our study defined logged sites as logging gaps only. Thus, smaller disturbed areas, such as skid trails or access roads, may have lowered the average recruit density across all logged areas. Additionally, skid trails or access roads have only marginal differences in canopy openness compared with understory forest. This is consistent with Soriano et al.'s [17] finding of a positive correlation between recruit density and canopy openness, as well as logging disturbance size. The threefold lower densities of productive trees in Madre de Dios compared to the rest of the Western Amazon region may also explain the low levels of natural regeneration across the 16 concessions studied here. We found only saplings in understory sites, with no seedlings present. These findings contrast with those of Myers et al. [1] in Bolivia who only observed seedlings and no saplings in understory forest. The lower density of mature trees noted in Peru may explain the relative infrequency of individuals encountered in the present study, and thus the difference in recruit size class. However, the presence of some saplings in the understory would suggest that recruits can reach a height above $1.3 \mathrm{~m}$ in this growth environment.

Interestingly, recruit density showed no significant relationship with distance to the nearest mature tree. A negative relationship was expected as dispersal by agoutis, the primary dispersal agent for the heavy Brazil nut, would likely have a limited range $[3,24,25]$. Instead, seedlings were noted at distances greater than $50 \mathrm{~m}$ from the nearest mature tree.

Recruit success is a function of establishment, survival, and growth of seedlings [5], which are influenced by a number of factors including dispersal, predation and herbivory, and local ecophysiological conditions. In the growth experiment, higher seedling growth rates in tree-fall gaps as compared to mature forest confirm Cotta et al.s [5] and Kainer et al's [23] findings that growth rate (height, total leaf area, and leaf number) are positively correlated with increasing light availability. Seedlings in gap environments had significantly higher growth rates than those in understory environments, yet interestingly, openness was not correlated with growth rate within gaps (though there was a positive relationship). Within understory environments, where average canopy openness reached a maximum of $11 \%$, there was a significant positive correlation between openness and growth, implying that at very low openness levels, growth is primarily limited by light availability, whereas in gap environments other factors may be more important in determining growth rate. Recruit success, then, was improved in gaps: both in higher recruit densities in logging gaps and in higher seedling growth rates in natural tree-fall gaps. This suggests that selective logging may improve conditions for Brazil nut recruitment success, by affecting establishment and subsequent growth.

Multiple-use forest management (MFM) for diverse products including timber, NTFPs, and ecosystem services has the potential to contribute to sustainable development while meeting forest conservation goals $[16,26]$. Recommended (i.e., low impact) selective logging practices aim to reduce forest disturbance [27], which can be compatible with NTFP extraction, particularly for light-demanding NTFP 

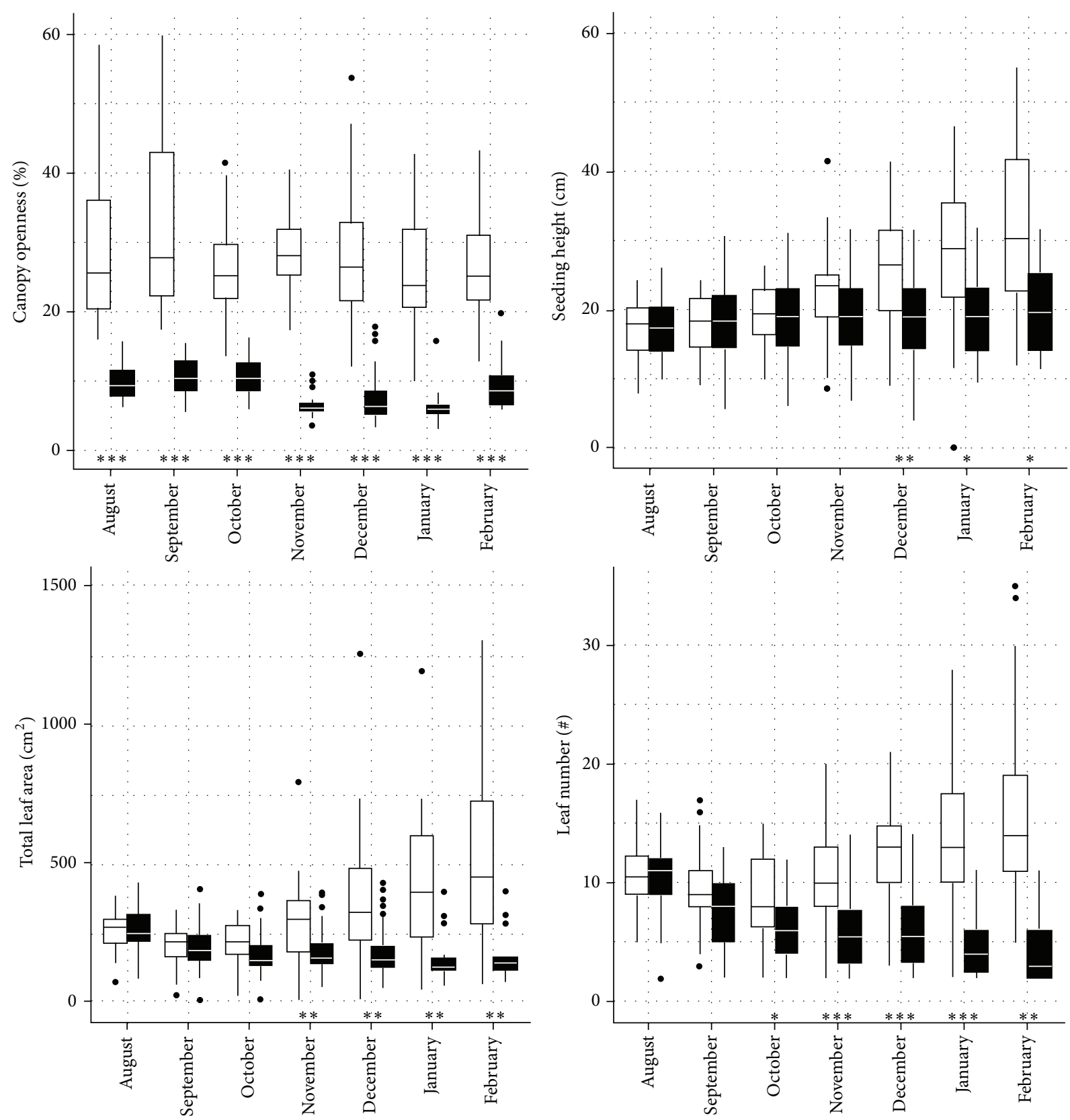

Location

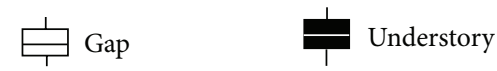

Location



FIGURE 2: Boxplots showing: openness in tree-fall and understory plots; seedling height in $\mathrm{cm}$ from ground; total leaf area in $\mathrm{cm}^{2}$; and leaf number versus measurement month (years 2011-2012). Black boxes represent seedlings in understory sites; white boxes represent seedlings in tree-fall gaps. Significance of difference is provided as $P$ value ${ }^{*}=<0.05,{ }^{* *}=<0.01$, and ${ }^{* * *}=<0.001$.

species [28-30] including Brazil nut [31]. Furthermore, selective logging and Brazil nut extraction have a high potential for integration including cooccurrence, high economic value, temporal segregation in harvest seasons, Brazil nut's legal protection from logging, and shared use of forest inventories $[14,31]$. In a review of the barriers to MFM, Guariguata et al. [32] identified the need to refine the scientific basis for assessing tradeoffs between extraction activities. This study contributes evidence to the ecological compatibility of the two activities.

However, the potentially critical role of logging intensity in determining sustainability of MFM remains murky. Although we were not able to measure logging intensity, our observations across the 16 Brazil nut concessions studied suggest that intensities did not exceed one timber tree per ha $\left(4-5 \mathrm{~m}^{3} / \mathrm{ha}\right)$, which is consistent with reported logging 
intensities in this region [19]. At higher intensities, one would expect Brazil nut recruitment densities to increase as light availability increased $[1,5]$ provided that logging practices avoid excessive damage to mature Brazil nut trees [33]. Further investigation is required to understand the interaction of different logging intensities and Brazil nut demographics to guide policy design of MFM.

\section{Conflict of Interests}

The authors declare that there is no conflict of interests regarding the publication of this paper.

\section{Acknowledgments}

The authors thank Rufo Bustamante Collado and Manuel Guariguata for their guidance, Missy Holbrook and Dylan Craven for their comments, Andrea Chavez, Angelica Almeyda Zambrano, and Mario Usca for their support, CAMDE Peru, William Moreno, and Ingrid Montalvo for the logistical support, Fauna Forever Tambopata, Chris Kirkby, and David Johnston for a home away from home, Martin and Thomas Rocek for their help with data analysis, Harvard College Research Program, David Rockefeller Center for Latin American Studies, Kennedy School of Government Sustainability Science Grant, and OEB grants in aid of undergraduate research for their generous funding support. The authors thank the anonymous reviewers for their critical feedback on earlier drafts of this paper.

\section{References}

[1] G. P. Myers, A. C. Newton, and O. Melgarejo, "The influence of canopy gap size on natural regeneration of Brazil nut (Bertholletia excelsa) in Bolivia," Forest Ecology and Management, vol. 127, no. 1-3, pp. 119-128, 2000.

[2] E. G. Ortiz, "Brazil nut (Bertholletia excelsa)," in Tapping the Green Market: Certification and Management of Non-Timber Forest Products, P. Shanley, S. A. Laird, and A. Guillén, Eds., pp. 61-74, Earthscan Publications, London, UK, 2002.

[3] J. M. T. Haugaasen, T. Haugaasen, C. A. Peres, R. Gribel, and P. Wegge, "Seed dispersal of the Brazil nut tree (Bertholletia excelsa) by scatter-hoarding rodents in a central amazonian forest," Journal of Tropical Ecology, vol. 26, no. 3, pp. 251-262, 2010.

[4] IIAP, Madre de Dios Camino Al Desarrollo Sostenible: Propuesta de Zonificación Económica Ecológica Como Base Para El Ordenamiento Territorial, Instituto de Investigaciones de la Amazonia Peruana (IIAP), Lima, Perú, 2001.

[5] J. N. Cotta, K. A. Kainer, L. H. O. Wadt, and C. L. Staudhammer, "Shifting cultivation effects on Brazil nut (Bertholletia excelsa) regeneration," Forest Ecology and Management, vol. 256, no. 1-2, pp. 28-35, 2008.

[6] GOREMAD, Plan Estrategico Regional del Sector Agrario Madre de Dios 2008-2015, 2005.

[7] Cámara Forestal de Bolivia, Anuario Estadístico del Sector Forestal de Bolivia 2006, Cámara Forestal de Bolivia, Santa Cruz, Bolivia, 2007.
[8] IBGE, "Produção da Extração Vegetale da Silvicultura," Instituto Brasileiro de Geografia e Estatística (IBGE), Rio de Janeiro, Brazil, 2010, http://www.ibge.gov.br.

[9] J. Escobal and U. Aldana, "Are nontimber forest products the antidote to rainforest degradation? Brazil nut extraction in Madre De Dios, Peru," World Development, vol. 31, no. 11, pp. 1873-1887, 2003.

[10] C. A. Peres, C. Baider, P. A. Zuidema et al., "Demographic threats to the sustainability of Brazil nut exploitation," Science, vol. 302, no. 5653, pp. 2112-2114, 2003.

[11] P. A. Zuidema and R. G. A. Boot, "Demography of the Brazil nut tree (Bertholletia excelsa) in the Bolivian Amazon: impact of seed extraction on recruitment and population dynamics," Journal of Tropical Ecology, vol. 18, no. 1, pp. 1-31, 2002.

[12] L. H. O. Wadt, K. A. Kainer, C. L. Staudhammer, and R. O. P. Serrano, "Sustainable forest use in Brazilian extractive reserves: natural regeneration of Brazil nut in exploited populations," Biological Conservation, vol. 141, no. 1, pp. 332-346, 2008.

[13] R. Scoles and R. Gribel, "The regeneration of Brazil nut trees in relation to nut harvest intensity in the Trombetas River valley of Northern Amazonia, Brazil," Forest Ecology and Management, vol. 265, pp. 71-81, 2012.

[14] A. E. Duchelle, M. R. Guariguata, G. Less, M. A. Albornoz, A. Chavez, and T. Melo, "Evaluating the opportunities and limitations to multiple use of Brazil nuts and timber in Western Amazonia," Forest Ecology and Management, vol. 268, pp. 3948, 2012.

[15] C. A. Kirkby, R. Giudice-Granados, B. Day et al., "The market triumph of ecotourism: an economic investigation of the private and social benefits of competing land uses in the Peruvian Amazon," PLoS ONE, vol. 5, no. 9, Article ID e13015, 2010.

[16] F. E. Putz, P. A. Zuidema, T. Synnott et al., "Sustaining conservation values in selectively logged tropical forests: the attained and the attainable," Conservation Letters, vol. 5, pp. 296-303, 2012.

[17] M. Soriano, K. A. Kainer, C. L. Staudhammer, and E. Soriano, "Implementing multiple forest management in Brazil nut-rich community forests: effects of logging on natural regeneration and forest disturbance," Forest Ecology and Management, vol. 268, pp. 92-102, 2012.

[18] M. W. Tobler, The ecology of the lowland tapir in Madre de Dios, Peru: using new technologies to study large rainforest mammals [Doctoral thesis], Texas A\&M University, 2008.

[19] R. E. Cossío-Solano, M. R. Guariguata, M. Menton, J. L. Capella, L. Rios, and P. Peña, "El aprovechamiento de madera en las concesiones castañeras (Bertholletia excelsa) en Madre de Dios, Perú," Un Análisis de Su Situación Normativa CIFOR Working Paper 60, 2011.

[20] P. E. Lemmon, "A new instrument for measuring forest overstory density," Journal of Forestry, vol. 55, pp. 667-668, 1956.

[21] G. S. Strickler, "Use of the densiometer to estimate density of canopy on permanent sample plots," USDA Forest Service Research Note No. 180, 1959.

[22] K. A. Kainer, L. H. O. Wadt, and C. L. Staudhammer, "Explaining variation in Brazil nut fruit production," Forest Ecology and Management, vol. 250, no. 3, pp. 244-255, 2007.

[23] K. A. Kainer, M. L. Duryea, N. C. de MacÊdo, and K. Williams, "Brazil nut seedling establishment and autecology in extractive reserves of Acre, Brazil," Ecological Applications, vol. 8, no. 2, pp. 397-410, 1998.

[24] C. A. Peres and C. Baider, "Seed dispersal, spatial distribution and population structure of Brazilnut trees (Bertholletia excelsa) 
in southeastern Amazonia," Journal of Tropical Ecology, vol. 13, no. 4, pp. 595-616, 1997.

[25] K. M. Silvius and J. M. V. Fragoso, "Red-rumped agouti (Dasyprocta leporina) home range use in an amazonian forest: implications for the aggregated distribution of forest trees," Biotropica, vol. 35, no. 1, pp. 74-83, 2003.

[26] T. Panayotou and P. Ashton, Not by Timber Alone: Economics and Ecology for Sustaining Tropical Forests, Island Press, Washington, DC, USA, 1992.

[27] D. P. Dykstra and R. Heinrich, FAO Model Code of Forest Harvesting Practice, Food and Agriculture Organization, Rome, Italy, 1996.

[28] J. Salick, A. Mejia, and T. Anderson, "Non-timber forest products integrated with natural forest management, Rio San Juan, Nicaragua," Ecological Applications, vol. 5, no. 4, pp. 878895, 1995.

[29] C. Romero, "Reduced-impact logging effects on commercial non-vascular pendant epiphyte biomass in a tropical montane forest in Costa Rica," Forest Ecology and Management, vol. 118, no. 1-3, pp. 117-125, 1999.

[30] L. Rist, P. Shanley, T. Sunderland et al., "The impacts of selective logging on non-timber forest products of livelihood importance," Forest Ecology and Management, vol. 268, pp. 5769, 2012.

[31] M. R. Guariguata, C. García-Fernández, D. Sheil et al., “Compatibility of timber and non-timber forest product management in natural tropical forests: perspectives, challenges, and opportunities," Forest Ecology and Management, vol. 259, no. 3, pp. 237-245, 2010.

[32] M. R. Guariguata, P. Sist, and R. Nasi, "Multiple use management of tropical production forests: how can we move from concept to reality?" Forest Ecology and Management, vol. 263, pp. 170-174, 2012.

[33] M. R. Guariguata, J. C. Licona, B. Mostacedo, and P. Cronkleton, "Damage to Brazil nut trees (Bertholletia excelsa) during selective timber harvesting in Northern Bolivia," Forest Ecology and Management, vol. 258, no. 5, pp. 788-793, 2009. 

